$\begin{gathered}\text { Науковий вісник НЛтУ України } \\ \text { Scientific Bulletin of UNFU } \\ \text { https://nv.nltu.edu.ua }\end{gathered}$
$\begin{array}{r}\text { https://doi.org/10.15421/40280828 } \\ \text { Article received } 11.10 .2018 \mathrm{p} .\end{array}$
$\begin{gathered}\text { Article accepted } 25.10 .2018 \mathrm{p} . \\ \text { ІІSSN 1994-7836 (print) } \\ \text { ISSN 2519-2477 (online) }\end{gathered}$

Т. О. Назірова, О. Б. Костенко

Харківський національний університет міського господарства ім. О. М. Бекетова, м. Харків, Україна

\title{
НЕЙРОНОМЕРЕЖЕВА ІНФОРМАЦІЙНА ТЕХНОЛОГІЯ ОПРАЦЮВАННЯ МЕДИЧНИХ ДАНИХ
}

Швидкий розвиток комп'ютерної техніки формує передумови для розробок нейрокомп'ютерів (тобто комп'ютерів 6-го покоління), які, за прогнозами в галузі штучного інтелекту, активно будуть використані для перероблення будь-якої інформації, за тими ж принципами, що й біологічні нейронні мережі - такі як людський мозок. Тому попит на використання нейромережеві технології поступово охоплює дедалі ширший коло користувачів зокрема й у галузі охорони здоров'я. Досліджено можливості застосування штучних нейронних мереж для оброблення даних регіональної охорони здоров'я. Нейронні мережі - потужний метод моделювання, що дає змогу відтворювати складні нелінійні залежності, що актуально для систем прийняття рішень управління пацієнтопотоком у медичних закладах. Запропоновано інформаційну технологію оброблення медичних даних за допомогою штучних нейронних мереж, що дасть змогу підвищити ефективність надання медичної допомоги під час профілактичних медоглядів, ніж відомі інформаційні технології класифікації. Розглянуті такі положення: принципи дії штучних нейронних мереж, переваги і недоліки їх використання та основні функції. Також наведено перспективи використання штучних нейронних мереж щодо класифікації пацієнтів для проходження профілактичного медичного огляду.

Ключові слова: медична інформаційна система; штучна нейронна мережа; дані регіональної охорони здоров'я; штучний інтелект.

Вступ. Широке впровадження інформаційних технологій у лікувальний та діагностичний процеси, інтеграція у світовий інформаційний простір є важливим компонентом реформування вітчизняної галузі охорони здоров'я. Це дасть змогу за порівняно короткий термін домогтися істотного підвищення ефективності роботи закладів охорони здоров'я, поліпшити якість лікування та діагностики. Робота медичних працівників значною мірою пов'язана зі заповненням великої кількості документів на паперових носіях. Виконання такої роботи призводить до значного витрачання робочого часу (за деякими оцінками - 25-50 \%) (Girosi, Meili \& Scoville, 2005).

Великого значення набувають завдання зі складною формалізацією, тобто такі, для яких алгоритм рішення або не є єдиним, або не дає змоги оцінити якість чи досяжність рішення. Нейромережеві технології покликані вирішувати завдання, що важко формалізуються, до яких, зокрема, зводиться більшість методик оброблення медичних даних. Передусім це пов'язано з тим, що досліднику доводиться аналізувати надвелику кількість різноманітних фактичних даних, для яких ще не створено математичної моделі (Nazirova \& Kostenko, 2017; Devarakonda, Mehta \& Tsou, 2017).

Аналіз останніх досліджень і публікацій. У науковій літературі існує чимало статей щодо застосування нейронних мереж у медицині, зокрема під час оброблення великих масивів даних та прогнозування розвит-

ку подій. Порівняння ефективності neural network 3 іншими методами аналізу здійснили такі вчені, як: F. Girosi, V. Murthy, Li Xiang, Grégoire Montavon, I. A. Mapкіна, К. В. Мельник.

Спираючись на емпіричні дані, автори дійшли висновку, що neural network $\epsilon$ оптимальним методом для моделювання будь-яких неперервних та нелінійних функцій, які не припускають жодних умов до вхідної інформації (Li, Ding \& Sun, 2017). У своїй роботі, присвяченій поєднанню технічного та фундаментального аналізу 3 нейронними мережами, I. А. Маркіна (Palm, 2016) навела кілька основних переваг останніх, виділивши числову природу neural network, що $є$ необхідним для оброблення масивів даних. Нейронні мережі працюють покроковим методом, який дає змогу використовувати нові дані для тренування мережі, щоб покращити попередні результати (Montavon, Samek \& Müller, 2017). Серед досліджень neural network для використання в обробленні інформації варто назвати праці Xiang Li (Li, Ding \& Sun, 2017), Grégoire Montavon (Montavon, Samek \& Müller, 2017), I. А. Маркіної (Palm, 2016) та К. В. Мельник (Melnik, 2015), які довели їх ефективність та дієвість для вирішення завдань класифікації та прогнозування в медицині (HFA-DB, 2012).

Постановка задачі. Нейронна мережа - це послідовність нейронів, з'єднаних між собою синапсами. Прототипом для створення нейронних мереж послужили бі-

\section{Інформація про авторів:}

Назірова Тетяна Олександрівна, здобувач, ст. інженер комп'ютерних систем ООО Метінвест Бізнес Сервіс Україна, м. Кривий Ріг. Email: freestar@ukr.net

Костенко Олександр Борисович, канд. фіз.-мат. наук, доцент, кафедра прикладної математики та інформаційних технологій. Email: ks42@ukr.net

Цитування за ДСтУ: Назірова Т. О., Костенко О. Б. Нейрономережева інформаційна технологія опрацювання медичних даних. Науковий вісник НЛту України. 2018, т. 28, № 8. С. 141-145.

Citation APA: Nazirova, T. O., \& Kostenko, O. В. (2018). Neural network information technology for the processing of medical data. Scientific Bulletin of UNFU, 28(8), 141-145. https://doi.org/10.15421/40280828 
ологічні нейронні мережі. Завдяки такій структурі система отримує здатність аналізувати і навіть запам'ятовувати різну інформацію. Нейронні мережі також здатні не тільки аналізувати вхідну інформацію, а й відтворювати іï зі своєї пам'яті. Їх використовують для вирішення складних завдань, які вимагають аналітичних обчислень подібних до тих, що робить людський мозок.

Найпоширенішими застосуваннями нейронних мереж є:

- класифікаиія - розподіл даних за параметрами. Наприклад, на вхід дається набір людей і потрібно вирішити задачу розподілення потоку пацієнтів, для проходження щорічних профілактичних оглядів. Цю роботу може зробити нейронна мережа, аналізуючи таку інформацію як: стать, вік, тип зайнятості та інші дані, що містяться в електронній медичній картці;

- передбачення - можливість прогнозування. Наприклад, прогнозування зростання або падіння пацієнтопотоку, грунтуючись на даних звернення до фахівців, епідемічної ситуації в регіоні тощо;

- розпізнавання - на сьогодні найширше застосування нейронних мереж. Використовується в багатьох медичних системах, для розпізнавання даних зі зображеннями обстежень. Наприклад, за даними IBM Watson аналізу результатів флюорографічних обстежень, площа кривої помилок алгоритму становила 0,788 .

Розв'язання задачі класифікації пацієнтопотоку для проходження профілактичних оглядів дасть змогу оптимізувати графіки зайнятості фахівців медичних установ, зменшити витрати часу на формальні дії та поліпшити якість надання медичних послуг населенню. Використання нейронної мережі для класифікації значно спростить оброблення неструктурованих або неповних даних пацієнтів, що в разі застосування класичних математичних моделей дає велику кількість етапів та значущі похибки.

Застосування штучних нейронних мереж для оброблення медичної інформації. Біологічний нейрон імітується у штучній нейронній мережі через активаційну функцію. У задачах класифікації (наприклад розподілення пацієнтопотоку по медоглядах) активаційна функція повинна мати характеристику "вмикача". Розглянемо таку подію: якщо на вхід подано більше ніж деяке значення, то вихід повинен змінювати стан, наприклад з 0 на 1, або -1 на 1. Це імітує "включення" біологічного нейрона. Як активаційну функцію зазвичай використовують сигмоїдальну функцію

$$
f(z)=\frac{1}{1+\exp (-a \cdot z)} .
$$

Ця формула - сигмоїдальна функція, де коефіцієнт "а" відповідає за регулювання ступеня стискання сигмоїди, залежно від рівня густоти населення в певному регіоні. Сигмоподібна функція, написана мовою Python, має такий вигляд (рис. 1). Програмний код функції нейронної мережі мовою Pуthon наведено нижче.

На рис. 2, де представлено функцію у вигляді графіка, можна побачити, що вона "активаційна" - зростає від 0 до 13 кожним збільшенням значення х. Сигмоїдальна функція є гладкою і безперервною. Це означає, що вона має похідну, що, водночас, є дуже важливим фактором для навчання алгоритму. Цей ефект і сприяє навчанню мережі на підстаі кореляцій вхідних і вихідних даних.

Для демонстрації багатофакторного оброблення даних штучними нейронними мережами, у ході дослідів було використано експериментальні анонімні дані анкет пацієнтів-донорів інформації. Опитування проводили за допомогою затвердженого на міжнародному рівні опитувальника "The World Health Organization Quality of Life (WHOQOL-100)" (VOZ, 2017). Ця методика оцінює відчуття людей у контексті їх культури і системи цінностей, а також їх особистих цілей, стандартів і інтересів. Методики WHOQOL було розроблено спільними зусиллями цілої низки центрів у різних країнах світу і широко протестовано, та містять 100 запитань. Експериментальні дані представлені у вигляді CSV-файлу, зі значеннями, розділеними комами, в якому кожен рядок відповідає одній анкеті.

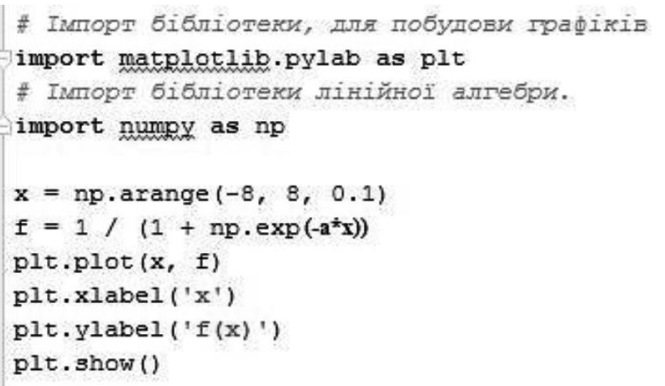

Рис. 1. Лістінг коду мовою Python

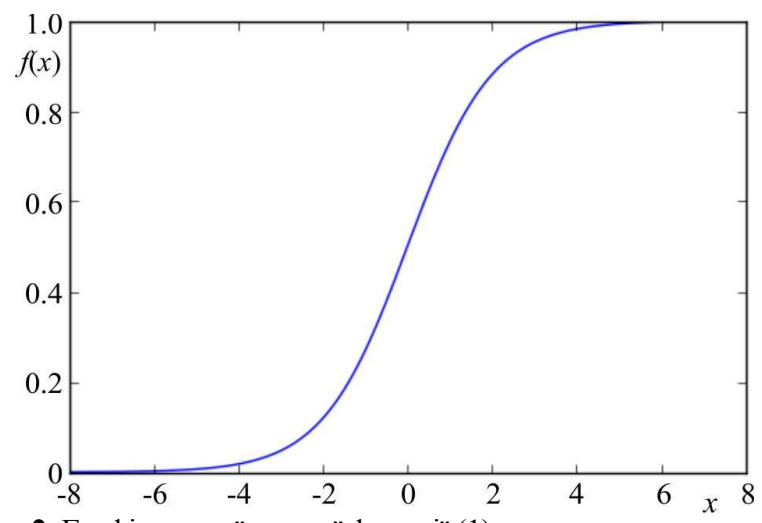

Рис. 2. Графік сигмоїдальної функції (1)

Для класифікації згідно з терміном медогляду та територіальної приналежності пацієнта анкета анонімного донора інформації містить такі дані (Nazirova \& Kostenko, 2018): 1) дата останнього медогляду; 2) дата народження; 3) адреса проживання: місто, вулиця, будинок; 4) рід занять, напрямок робіт.

Подальшими завданнями поставленої задачі потрібно вирішити питання інтеграції попиту необхідності проходження медогляду та можливостей регіонального лікувального закладу надати потрібні обсяги доцільних обстежень і досліджень. Для реалізації системи класифікації експериментального набору даних будемо використовувати багатошарову повнозв'язкову штучну нейронну мережу (багатошаровий персептрон), в якій кожен нейрон довільного шару пов'язаний 3 усіма нейронами попереднього шару.

Багатошаровий персептрон містить три типи шарів нейронів: вхідний, прихований i вихідний. Кожен нейрон мережі має гладку нелінійну функцію активації. Багатошарові нелінійні нейронні мережі дають змогу формувати складніші зв'язки між входами і виходами, ніж одношарові лінійні. Доведено, що тришарова нейронна мережа $з$ одним прихованим шаром може бути навчена апроксимувати із довільною точністю будьяку безперервну функцію (Montavon, Samek \& Müller, 2017). 
Опишемо структуру моделі нейронної мережі. Визначимо вхідний, вихідний і приховані шари. Нейронна мережа має щільну структуру - кожен нейрон пов'язаний $з$ усіма нейронами наступного шару. Для побудови нейронної мережі 3 достатньою узагальнювальною здатністю, необхідно визначити міру Вапніка-Червоненкіса для цієї топології нейронної мережі (Montavon, Samek \& Müller, 2017), згідно з такою формулою:

$$
2\left[\frac{K}{2}\right] N \leq V C_{d i m} \leq 2 N_{w}\left(1+\lg N_{n}\right),
$$

де: $N$ - розмірність даних на вході; $K$ - кількість нейронів в прихованому шарі; $N_{w}$ - загальна кількість ваг мережі; $N_{n}$ - загальна кількість нейронів мережі.

Щоб запобігти "перенавчанню" нейронної мережі, розмірність (кількість нейронів) прихованого шару повинна бути нижчою, або дорівнювати розмірності навчальної вибірки. Шар додається до моделі (рис. 3) методом add(). Для вхідного шару необхідно вказати кількість ознак input_dim, яке в нашому випадку дорівнює 4:

model.add (Dense $(12$, input_dim $=4$, activation = 'relu'))

Рис. 3. Лістінг коду додавання шару

Якщо набори ознак утворюють багатовимірну таблицю, то замість параметра input_dim можна використовувати параметр input_shape, що приймає кортеж 3 кількістю елементів в кожному з вимірів. Як функцію активації для всіх шарів, окрім вихідного, будемо використовувати функцію ReLU - rectified linear unit(3).

$$
\delta(x)=\max (0, x) .
$$

Ії̈ похідна дорівнює або одиниці, або нулю, і тому не може призвести до розростання або загасання градієнтів. Більше того використання цієї функції призводить до проріджування ваг (лістінг - рис. 4, графік - рис. 5).

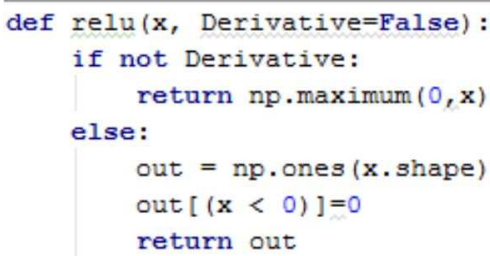

Рис. 4. Лістінг коду функції функцію ReLU мовою Python

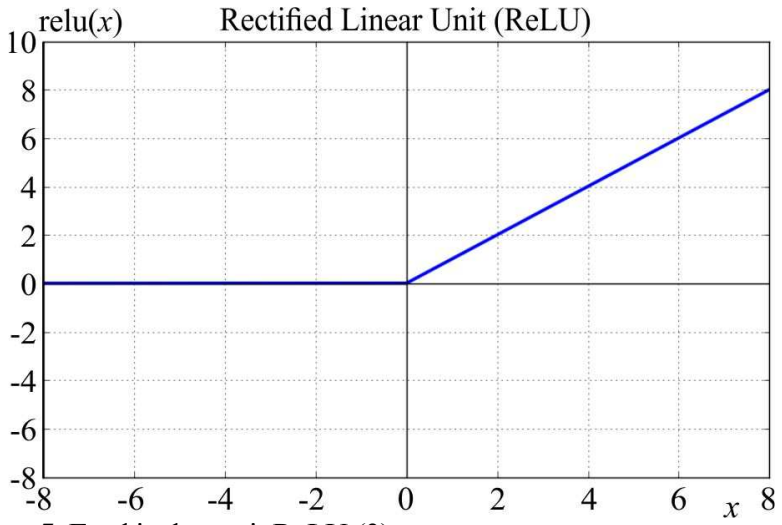

Рис. 5. Графік функції ReLU (3)

Для вихідного шару скористаємося сигмоїдальною функцією для визначення кінцевої ознаки необхідності проходження медогляду. Спроектована нейронна мережа (рис. 6) містить вхідний шар, один прихований шар і вихідний шар. Вхідний шар нейронної мережі має n-ну кількість нейронів, що буде відповідати кількості полів таблиці анкети. Вихідний шар має один нейрон, відповідно настанню необхідності проходження медогляду або відсутності такої необхідності в заданий проміжок часу. Пряме поширення сигналу проводиться пошарово, починаючи із вхідного шару, при цьому розраховується сума вхідних сигналів для кожного нейрона і за допомогою функції активації генерується відгук нейрона, який поширюється в наступний шар 3 урахуванням ваги міжнейронного зв'язку. Внаслідок виконання цього етапу можливо отримати вектор вихідних значень нейронної мережі. Наступний етап навчання - обчислення помилки нейронної мережі як різниці між очікуваним і дійсним вихідними значеннями.

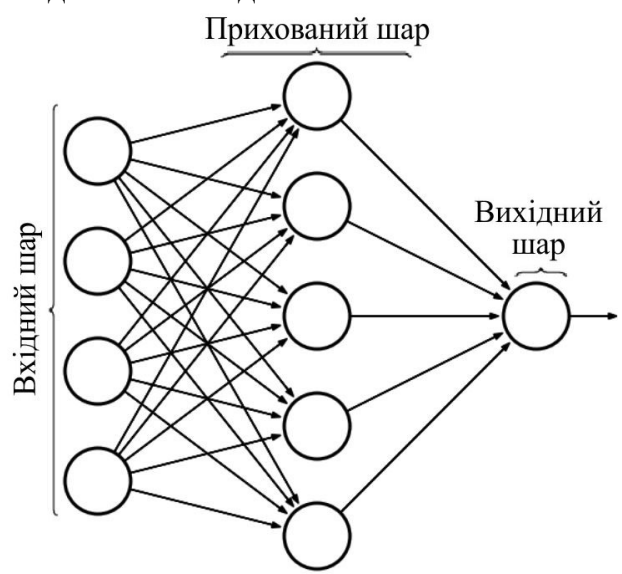

Рис. 6. Архітектура отриманої нейронної мережі

Для навчання штучної нейронної мережі застосовувався алгоритм зворотного поширення помилки (Montavon, Samek \& Müller, 2017). У ньому обчислюється помилка, як вихідного шару, так і кожного нейрона навченої мережі, а також корекція ваги нейронів відповідно до їх поточних значень.

На першому кроці цього алгоритму вага всіх міжнейронних зв'язків ініціюється випадковими значеннями (від 0 до 1). Після ініціалізації ваги в процесі навчання нейронної мережі виконуються такі кроки:

- пряме поширення сигналу;

- обчислення помилки нейронів останнього шару;

- зворотне поширення помилки.

Отримані значення помилок поширюються від останнього, вихідного шару нейронної мережі, до першого. При цьому обчислюються величини корекції ваги нейронів залежно від поточного значення ваги зв'язку, швидкості навчання і помилки, внесеної даними нейроном. Після завершення цього етапу кроки описаного алгоритму повторюються доти, поки помилка вихідного шару не досягне певного значення.

Програмний код функції нейронної мережі мовою Python, $з$ коментарями наведений у лістингу нижче.

Результати навчання i тестування спроектованої нейронної мережі показують можливість її застосування для вирішення завдання класифікації пацієнтопотоку щодо розподілення профілактичних медичних оглядів. Результати дослідження дають змогу зробити висновок про те, що запропонована штучна нейромережева система здатна $з$ високою ймовірністю розподілити дані на окремі групи і зробити конкретні висновки та припущення щодо кожної групи пацієнтів, за відносно невеликої кількості помилок. Так користувач медичної установи отримує можливість аналізувати групи даних і робити самостійні висновки про тенденції всередині кожної групи.

Висновки. Емпіричні результати класифікації пацієнтопотоку експериментальних анкетних даних, отриманих від донорів інформації за допомогою штучної 
нейронної мережі, доводять ефективність використання цього математичного апарату на рівні як регіональних медичних установ, так і для управління галуззю загалом. Апроксимуючі властивості штучної нейронної мережі доводять можливість врахування випадкових помилок та інших біхевіористичних факторів при заповнені первинної документації, що впливають на визна- чення часового періоду настання випадку необхідності медичного огляду. Результати навчання і перевірки працездатності спроектованих нейронних мереж показують їх успішне застосування для вирішення поставлених завдань і здатність знаходити складні закономірності та взаємозв'язки між неструктурованими масивами даних.

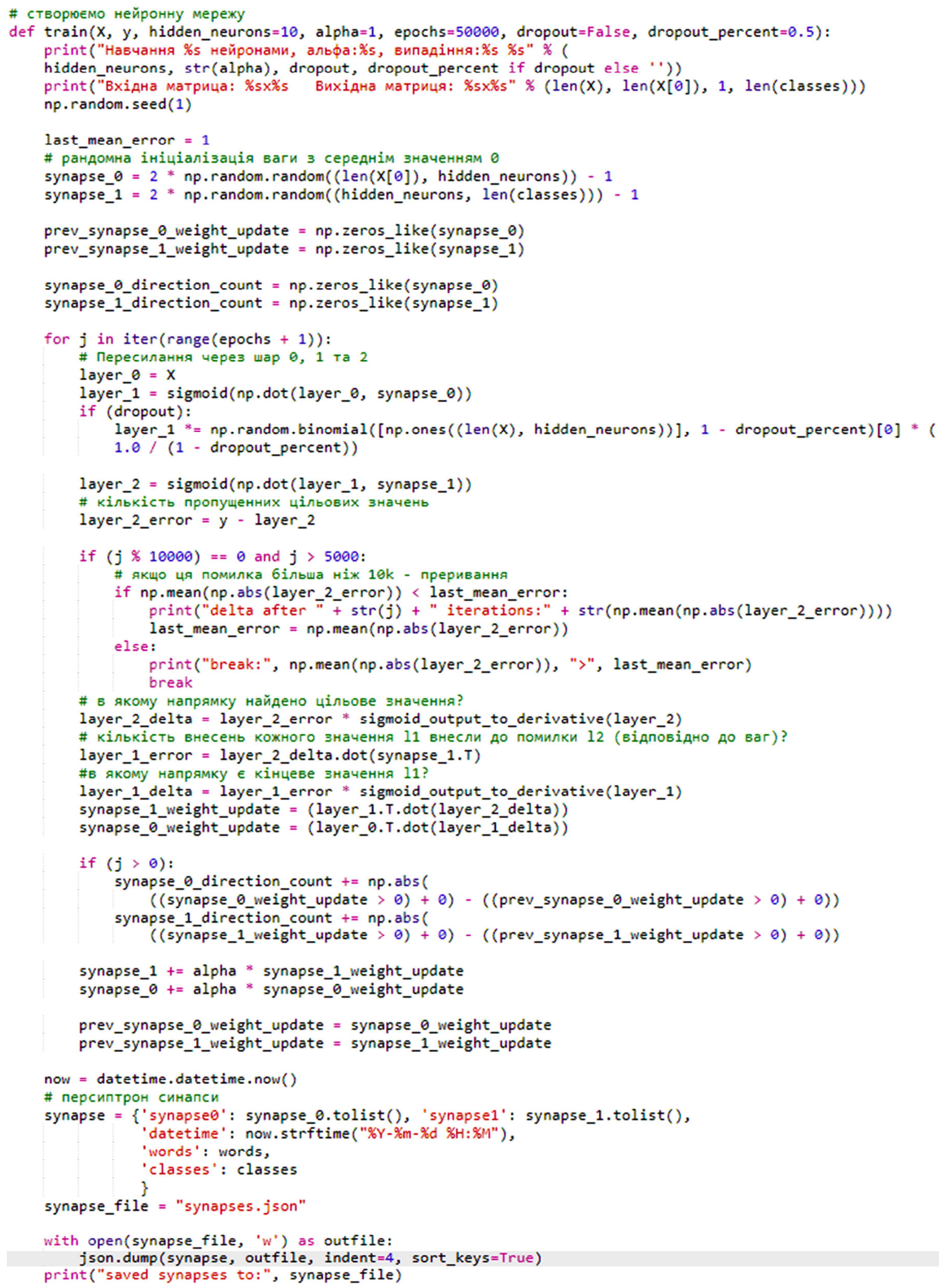

Лістинг. Програмний код функції нейронної мережі мовою Руthon

Вагомим аргументом на користь цього підходу є те, що штучні нейронні мережі здатні швидко адаптуватися до нових даних, не потребують залучення високоопла- чуваних та кваліфікованих експертів, дають змогу швидко виявити приховані закономірності, у зручному вигляді представити результати оброблення інформації. 
Подальше впровадження запропонованого в роботі підходу щодо класифікації пацієнтів, дасть змогу вибрати пріоритетні напрямки необхідного реформування у регіонах України, здійснювати постійний моніторинг стану здоров'я населення, що позитивно впливатиме на загальний стан здоров'я нації. Також це дасть змогу збирати дані щодо необхідних послуг в окремих районах, точніше розраховувати графіки завантаження медичних працівників та контролювати якість медичної допомоги.

Перспективи подальших досліджень. Отримані результати доцільно використовувати в подальших дослідженнях. На майбутнє планується розробка інтеграційної нейронної мережі класифікації пацієнтопотоку та можливостей регіонального лікувального закладу в наданні потрібних обсягів обстежень та досліджень. Також перспективною $є$ можливість розробки, на підстаі отриманих параметрів, технології інтероперабельності компонентів медичних даних.

\section{Перелік використаних джерел}

Devarakonda, Murthy V., Mehta, Neil, \& Tsou, Ching-Huei. (2017). Automated problem list generation and physicians perspective from a pilot study. International Journal of Medical Informatics. https://doi.org/10.1016/j.ijmedinf.2017.05.015

Girosi, F., Meili, R., \& Scoville, R. (2005). Extrapolating evidence of health information technology savings and costs. Health affairsvol. https://doi.org/10.1377/hlthaff.24.5.1103
HFA-DB. (2012). European health for all database. Retrieved from: http://data.euro.who.int/hfadb/.

Li, Xiang, Ding, Qian, \& Sun, Jian-Qiao. (2017). Remaining useful life estimation in prognostics using deep convolution neural networks. Reliability Engineering \& System Safety. https://doi.org/10.1016/j.ress.2017.11.021

Melnik, K. V. (2015). Primenenie algoritma kollaborativnoi filtratcii dlia obrabotki meditcinskikh dannykh. Bulletin of the National Technical University "Kharkiv Polytechnic Institute", 2(1111), 193-198. [In Russian].

Montavon, Grégoire, Samek, Wojciech, \& Müller, Klaus-Robert. (2017). Methods for interpreting and understanding deep neural networks. Digital Signal Processing. https://doi.org/10.1016/j.dsp.2017.10.011

Nazirova, T. O., \& Kostenko, O. B. (2017). Overview of ehealth development models and existing medical information systems. problems of creating a single medical information space. Scientific Bulletin of UNFU, 27(10), 123-131. https://doi.org/10.15421/40271027

Nazirova, T. O., \& Kostenko, O. B. (2018). Instrumentalnyi analiz demohrafichnykh pokaznykiv u medychnii informatsiinii systemi. Bulletin of the National Technical University "Kharkiv Polytechnic Institute". Series "Mathematical Modeling", 3(1279), 81-88. [In Ukrainian].

Palm, Günther. (2016). Neural Information Processing in Cognition: We Start to Understand the Orchestra, but Where is the Conductor? Front Comput Neurosci. https://doi.org/10.3389/fncom.2016.00003

VOZ. (2017). Vsesvitnia orhanizatsiia okhorony zdorovia. Retrieved from: http://www.who.int/ru/. [In Ukrainian].

Т. А. Назирова, А. Б. Костенко

Харьковский наииональный университет городского хозяйства им. А. Н. Бекетова, г. Харьков, Украина

\section{НЕЙРОСЕТЕВАЯ ИНФОРМАЦИОННАЯ ТЕХНОЛОГИЯ ОБРАБОТКИ МЕДИЦИНСКИХ ДАННЫХ}

Быстрое развитие компьютерной техники формирует предпосылки для разработки нейрокомпьютеров (то есть компьютеров 6-го поколения), которые, по прогнозам в области искусственного интеллекта, активно будут использованы для обработки любой информации, по тем же принципам, что и биологические нейронные сети - такие как человеческий мозг. Поэтому спрос на использование нейросетевых технологий постепенно охватывает все более широкий круг пользователей, в том числе и в области здравоохранения. Исследованы возможности применения искусственных нейронных сетей для обработки данных регионального здравоохранения. Нейронные сети - мощный метод моделирования, который даст возможность воспроизводить сложные нелинейные зависимости, что актуально для систем принятия решений при управлении пациентопотоками в медицинских учреждениях. Предложена информационная технология обработки медицинских данных с помощью искусственных нейронных сетей, что позволит повысить эффективность оказания медицинской помощи при профилактических медосмотрах, чем известные информационные технологии классификации. Рассмотрены следующие положения: принципы действия искусственных нейронных сетей, преимущества и недостатки их использования и основные функции. Также приведены перспективы использования искусственных нейронных сетей для классификации пациентов для прохождения профилактического медицинского осмотра.

Ключевые слова: медицинская информационная система; искусственная нейронная сеть; данные регионального здравоохранения; искусственный интеллект.

T. A. Nazirova, A. B. Kostenko

O. M. Beketov National University of Urban Economy, Kharkiv, Ukraine

\section{NEURAL NETWORK INFORMATION TECHNOLOGY FOR THE PROCESSING OF MEDICAL DATA}

The aim of the article is to investigate the possibility of using artificial neural networks for processing regional health data. The spread of using computers in many business units in economic activity has significantly developed in recent years. Such a development is due to the most significant developments in recent years of so-called artificial intelligence and its applications. Artificial intelligence is defined as the use of computer in the simulation of human intelligence information (experience)-based computer programs through which a decision can be reached similar to human decision. One of the main biomedical problems lies in detecting dependencies in semi-structured data. Modern medicine rushes away from verbal description towards formalized processes, mathematical models and information technologies. These adaptive learning algorithms can handle diverse types of medical data and integrate them into categorized outputs. Diagnostic and prognostic tasks cannot be solved without creation of appropriate informative environment. It enables settling the problems of data and knowledge representation, seeking dependencies, and creating decision rules. The neural network is a new and promising computational technology that provides new approaches to solving problems in various scientific and social spheres of society. The interest in artificial neural networks has renewed in late eighties due to the need to process data in a manner that stimulates human mind, the progress in computer technology and neurology that resulted in greater understanding of human brain structure. This article discusses the nature of neural networks, especially their ability to training (setting of architecture and synaptic connections). An effective neural network training algorithm is provided. The authors also reveal the development prospects of application and use of artificial neural networks to apply the distribution of patients for a preventive medical examination. The use of artificial intelligence, in particular the use of artificial neural networks, to solve similar problems will help improve the quality of medical institution services.

Keywords: medical informatics system; artificial neural network; regional health data; artificial intelligence. 